\title{
Designing Surveys for $\mathrm{HCl}$ Research
}

Hendrik Müller

Google Australia Pty Ltd.

5/48 Pirrama Road

Pyrmont, NSW 2009, Australia

hendrik82@gmail.com

\author{
Aaron Sedley \\ Google, Inc. \\ 1600 Amphitheatre Parkway \\ Mountain View, CA 94041, US \\ asedley@gmail.com
}

\begin{abstract}
Online surveys are widely used in human-computer interaction $(\mathrm{HCl})$ to gather feedback and measure satisfaction; at a glance many tools are available and the cost of conducting surveys appears low. However, there is a wide gap between quick-and-dirty surveys, and surveys that are properly planned, constructed, and analyzed. This course examines survey research approaches that meet $\mathrm{HCl}$ goals, selecting the appropriate sampling method, questionnaire design best practices, identifying and avoiding common survey biases, and questionnaire evaluation. Attendees will gain an appreciation for the breadth and depth of surveys in $\mathrm{HCl}$, combined with keys to conducting valid, reliable, and impactful survey research themselves.
\end{abstract}

\section{Author Keywords}

Surveys; User Experience; Research Methodology; Questionnaire Design; Questionnaire Biases

\section{ACM Classification Keywords}

H.5.m [Information interfaces and presentation (e.g., $\mathrm{HCl}$ )]: Miscellaneous.

\section{Course description}

Surveys, now commonplace on the Web, allow researchers to make inferences about an entire population by 
gathering information from a small subset of the larger group. Surveys can gather insights about people?s attitudes, perceptions, intents, habits, awareness, experiences, and characteristics, both at significant moments in time and over time. Even though they are easy to administer, there is a wide gap between quick-and-dirty surveys and surveys that are properly planned, constructed, and analyzed [4].

Course attendees, either new to surveys or somewhat experienced but interested in the latest advances, will gain a practical understanding of the survey research lifecycle, from goals to planning, sampling considerations, questionnaire design, and evaluation $[2,3,1,5]$. This course will also focus on demonstrating common questionnaire biases while providing best practices on how to minimize them. The role of survey research within $\mathrm{HCl}$ will also be discussed by highlighting common applications and by examining frequently used standardized questionnaires to measure usability and other aspects within $\mathrm{HCl}$. The course will combine lecture material with relevant real-world examples; a major portion will be dedicated to interactive group activities during which attendees will apply some of the learned material to reviewing and revising example survey questions. No formal prerequisites are required to attend this course.

\section{Instructor backgrounds}

Hendrik Müller (Mueller) is a senior user experience researcher at Google, Inc. currently in Sydney, Australia. He leads user research for Google Drive, supports Google Docs, and previously worked on Google Health and several other products. Hendrik received his master?s degree in Human-Computer Interaction from the Georgia Institute of Technology in Atlanta, USA, in 2007.
Aaron Sedley is a senior user experience researcher at Google, Inc. in Mountain View, focused on tracking and analyzing user attitudes via surveys. He currently leads survey research within Search. Prior to joining Google in 2003, Aaron held research positions with New York Times Digital, Young \& Rubicam, and the Carnegie Endowment for International Peace. He earned a bachelor's degree in Government from Wesleyan University in 1995.

\section{Acknowledgements}

We would like to thank Jon Krosnick and Mick Couper for providing a wealth of methodological information and guidance, and Robin Jeffries and Ed Chi for their input and encouragement.

\section{References}

[1] Couper, M. P. Designing Effective Web Surveys, 1st ed. Cambridge University Press, New York, NY, USA, 2008.

[2] Groves, R., Fowler, F., Couper, M., Lepkowski, J., Singer, E., and Tourangeau, R. Survey Methodology, 2nd Edition. Wiley Series in Survey Methodology. John Wiley \& Sons, Hoboken, NJ, USA, 2011.

[3] Marsden, P., and Wright, J. Handbook of Survey Research. Emerald Group Publishing, Bingley, UK, 2010.

[4] Müller, H., Sedley, A., and Ferrall-Nunge, E. Survey research in $\mathrm{HCl}$. In Ways of Knowing in $\mathrm{HCl}$, J. Olson and W. Kellogg, Eds. Springer, New York, NY, USA, 2014, 229-266.

[5] Tourangeau, R., Rips, L., and Rasinski, K. The Psychology of Survey Response. Cambridge University Press, Cambridge, UK, 2000. 